\title{
Mini-KiSS Online: an Internet-based intervention program for parents of young children with sleep problems - influence on parental behavior and children's sleep
}

\author{
This article was published in the following Dove Press journal: \\ Nature and Science of Sleep \\ 9 March 2012 \\ Number of times this article has been viewed
}

\author{
Angelika A Schlarb ${ }^{1,2, *}$ \\ Isabel Brandhorst ${ }^{1, *}$ \\ 'University of Tuebingen, Faculty \\ of Science, Department of Psychology, \\ Tuebingen, ${ }^{2}$ University of Koblenz- \\ Landau, Department of Psychology, \\ Landau, Germany \\ *The authors contributed equally \\ to this work
}

Purpose: Behavioral sleep problems are highly common in early childhood. These sleep problems have a high tendency to persist, and they may have deleterious effects on early brain development, attention, and mood regulation. Furthermore, secondary effects on parents and their relationship are documented. Negative parental cognition and behavior have been found to be important influencing factors of a child's behavioral sleep problems. Therefore, in the current study we examined the acceptance and efficacy of a newly developed Internet-based intervention program called Mini-KiSS Online for sleep disturbances for children aged 6 months to 4 years and their parents.

Patients and methods: Fifty-five children (54.54\% female; aged 8-57 months) suffering from psychophysiological insomnia or behavioral insomnia participated in the 6-week online treatment. Sleep problems and treatment acceptance were examined with a sleep diary, anamnestic questionnaires, a child behavior checklist (the Child Behavior Checklist 1.5-5), and treatment evaluation questionnaires.

Results: The evaluation questionnaires showed a high acceptance of Mini-KiSS Online. Parents would recommend the treatment to other families, were glad to participate, and reported that they were able to deal with sleep-related problems of their child after Mini-KiSS Online. Parental behavior strategies changed with a reduction of dysfunctional strategies, such as staying or soothing the child until they fell asleep, allowing the child to get up again and play or watch TV, or reading them another bedtime story. Frequency and duration of night waking decreased as well as the need for external help to start or maintain sleep. All parameters changed significantly, not only in the questionnaires but also in the sleep diary.

Conclusion: Mini-KiSS Online is shown to be a highly accepted and effective treatment to change parental behavior and reduce behavioral sleep problems in early childhood.

Keywords: insomnia, childhood, behavioral insomnia of childhood, online treatment, parental behavior

\section{Introduction}

Sleep problems, such as bedtime resistance or frequent night waking, are highly common in young children. During the first years, the prevalence rate of sleep problems amongst children is between $9 \%$ and $54.2 \% .^{1-6}$

Etiological factors for sleep disturbances in early childhood are the absence of a self-soothing competence of the child and parent-child interaction, such as nursing, rocking, or comforting to sleep, as well as co-sleeping., ${ }^{2,7-10}$ Furthermore, negative 
parental cognition seems to have a significant influence on child sleep behavior and may be responsible for sleep problems. Parental cognition with regard to difficulties in limit-setting is associated with a poor sleep quality of the child, ${ }^{11}$ even if these cognitions are assessed prenatally, as shown by Tikotzky and Sadeh. ${ }^{12}$

Several studies have shown that sleep problems in infancy may persist after 2-3 years ${ }^{13}$ and become chronic. ${ }^{4,9,14,15}$ This risk also exists for 8-month-old children. ${ }^{6}$ Moreover, it has to be considered that disrupted and disturbed sleep has deleterious effects on early brain development, memory consolidation and learning processes, ${ }^{16-18}$ attention, and behavior and mood regulation, especially at this young age., ${ }^{319-21}$ Several studies have documented not only effects on children, but also secondary effects on parents - mostly on mothers in the form of maternal depression ${ }^{7,9,22-26}$ - and on the parental relationship. . 1,3,27,28 $^{-1}$

Given the high impact of sleep disturbances on children and parents, early treatment is necessary for the healthy development of the child and parental health. Three-quarters of parents would like to change their child's sleep..$^{29}$ Parents mostly seek help from primary care providers. ${ }^{30}$ Although some pediatricians are confident in their ability to manage sleep problems, such as insomnia or nightmares, they do not have the time to provide effective treatment. ${ }^{30-33}$

In the last decades, a number of onsite treatment strategies for infants and toddlers concerning bedtime resistance, problems falling asleep, as well as night waking have been developed and show high acceptance and efficacy. ${ }^{26,27,34,35}$ In general, sleep-specific parental education consists of two components: first, cognitive components, ie, modifying the expectations, interpretation, and emotion regarding the child's sleep-related behavior, needs, and reactions; second, behavioral components, ie, modifying the child's responses in order to influence the child's learned reactions, expectations, and behavior. ${ }^{27,35}$ The amount of face-to-face interventions available for parents with young children is limited; in contrast, the Internet has become a widely used resource for parents. About two-thirds of a community sample use the Internet to find health-related information. ${ }^{36}$ In recent years, a growing number of studies have shown that the Internet can be effectively used for the assessment and treatment of various medical and behavioral problems ${ }^{37-41}$ as well as adult sleep disorders, ${ }^{42,43}$ especially insomnia. ${ }^{44}$ Only recently, Mindell and colleagues used parental education and additional bedtime routines provided via the Internet in a study assessing mild to moderate sleep-disturbed infants and toddlers. ${ }^{45}$ The online feedback included a single normative comparison of the child's sleep to other children and brief customized advice on how caregivers can help their children to sleep better at night. The bedtime routine consisted of three steps over 2 weeks, including a bath, a massage, and quiet activities. Significant improvements were observed in sleep onset latency, sleep continuity, and mothers' confidence in managing their child's sleep..$^{45}$

There is an increasing demand to evaluate the process of therapeutic change and to discover central mechanisms of change in therapeutic effectiveness research. ${ }^{46-50}$ Therefore, we explored parental perception of their child's sleep improvement during treatment.

To our knowledge, there is no evaluated online treatment available in the German language that provides scientifically based information and behavior strategies for parents. The overall objective of the current study was to examine the acceptance and efficacy of a newly developed Internet-based intervention for sleep disturbances for children aged 6 months to 4 years and their parents. Therefore, we adapted the Mini-KiSS treatment, creating an online version according to the criteria of the American Academy of Sleep Medicine. ${ }^{26,51}$

We hypothesized that the treatment (1) would be well accepted, (2) would improve the sleep of infants and toddlers, and (3) that parents would be more able to overcome difficult sleep-specific situations.

\section{Materials and methods Participants}

Overall, the parents of 55 children aged 6 months to 4 years suffering from psychophysiological insomnia or behavioral insomnia (limit-setting sleep disorder or sleep onset association disorder) participated in this study. Participants were recruited through sleep laboratories and pediatric centers in Germany and an article published in a popular parent magazine in Germany. Children were excluded if there were reasonable suspicions for physical sleep problems on the basis of the anamnestic questionnaire (eg, related to breathing). One hundred and twenty families ordered information about the online treatment, 52 families applied for it, two of them participated as single mothers, three of them participated with twins or siblings. The age of the 55 children ( $54.54 \%$ female) ranged from 8 to 57 months with a mean age of 19.29 months (standard deviation $[\mathrm{SD}]=10.62$ ). $27.3 \%$ were aged between 6 and 12 months, 56.4\% aged between 13 and 24 months, and $16.4 \%$ aged between 24 and 60 months. See Table 1 for demographic information of the parents. 
Table I Demographic variables of the parents

\begin{tabular}{lll}
\hline Variable & $\begin{array}{l}\text { Mothers } \\
(\mathbf{N}=\mathbf{5 2})\end{array}$ & $\begin{array}{l}\text { Fathers } \\
(\mathbf{N}=\mathbf{5 2})\end{array}$ \\
\hline Age, (years) & & \\
$\quad$ Range & $22-4 \mathrm{I}$ & $25-60$ \\
$\quad$ Mean (SD) & $32.17(4.36)$ & $35(6.34)$ \\
Education, (number of persons) & & \\
$\quad$ Secondary general school & 6 & 6 \\
Intermediate school & 12 & 14 \\
Grammar school & 14 & 8 \\
University & 20 & 20 \\
Unknown & 0 & 4 \\
Employment, (number of persons) & & \\
Unemployed (intended) & 30 & 0 \\
Unemployed (unintended) & 2 & 0 \\
Part time & 16 & 2 \\
Full time & 4 & 49 \\
Unknown & 0 & 1 \\
\hline Abreviations: N, Nis &
\end{tabular}

Abbreviations: N, Number; SD, Standard Deviation.

\section{Classification of sleep disorders}

The inclusion criteria for the study were a parent-identified sleep problem (behavioral insomnia or psychophysiological insomnia) or sleep disorders according to Gaylor and colleagues with respect to the child's age. ${ }^{52}$ Thus, sleep onset insomnia is defined as sleep onset latency of more than 30 minutes for children from 12 to 23 months of age and as sleep onset latency of more than 20 minutes for children of 24 months and older. In addition, according to Gaylor et al, the presence of one parent or multiple refusals to go to bed are factors for diagnosing sleep onset insomnia. ${ }^{52}$ To diagnose sleep maintenance insomnia, subjects aged 12 to 23 months need to wake up at least twice ( $\geq 10$ minutes) after sleep onset; subjects of 24 months and older need to wake up at least once ( $\geq 10$ minutes), with a minimum of 20 minutes in sum for the whole night. According to Gaylor et al, sleep disorders are diagnosed when symptoms of sleep onset insomnia or sleep maintenance insomnia occur at least twice a week. ${ }^{52}$ All these sleep problems had to persist over a minimum period of 6 weeks.

In this study, the criteria according to Gaylor et al were expanded for children up to 23 months of age so that children under the age of 12 months could be included. ${ }^{52}$ The majority of children in this study were affected by sleep maintenance insomnia ( $\mathrm{N}=27 ; 49.1 \%)$, whereas a minority were affected by sleep onset insomnia $(\mathrm{N}=3 ; 5.5 \%)$. Fifteen children $(27.2 \%)$ were affected by both kinds of insomnia. The remaining ten children (18.2\%) were affected by sleep difficulties according to parental reports, but did not fulfill the criteria according to Gaylor et al. ${ }^{52}$

\section{Measurements}

All measurements were completed by the parents before and after treatment. They were instructed that responses should be made consistently by the same parent. Families accessed the measurements and online intervention from their home computer via a free-standing study website. Parents were provided with an individual password to access treatment.

\section{Anamnestic questionnaire (Mini-KiSS Online Questionnaire)}

The anamnestic questionnaire (Mini-KiSS Online Questionnaire) was constructed to investigate demographic (eg, age, sex, occupation) and diagnostic information (eg, amount/ duration of night waking, sleep onset latency), sleep hygiene factors (eg, child watches TV in bed), as well as parental behavior regarding sleep situation (eg, "What do you do if your child refuses to sleep?"). The questionnaire consisted of eleven sections (information about the child, family, sleep environment, sleep onset situation, night waking, parental behavior, situation in the morning, daily behavior of the child, recent life events, stress during pregnancy, regulation and temperament of the child). In sum, the questionnaire was based on 44 items. This questionnaire was used to diagnose sleep disorders and evaluate parental behavior changes before and after the Mini-KiSS Online treatment.

\section{Sleep diary}

A sleep diary was implemented in accordance with recommendations of the German Society of Sleep Medicine; ${ }^{53}$ it included components such as the sleep onset situation (duration of the going-to-bed ritual, use of parental support to fall asleep, time of going to bed, time of turning off the light, sleep onset latency) and the sleep maintenance situation (frequency and duration of night waking, if parents had to get up, if child needed external support or aliment to maintain sleep), nocturnal feeding procedures, overall night-time sleep duration, co-sleeping, waking time in the morning, use of medication, time and duration of daytime sleep, and information about special events. All diaries were completed over a period of 2 weeks.

\section{Child behavior checklist (CBCL I.5-5)}

The Child Behavior Checklist 1.5-5 (CBCL 1.5-5) by Achenbach and Rescorla was used to evaluate the sleep behavior of the children. ${ }^{54}$ This questionnaire refers to the last 2 months and consists of 99 items allocated to seven subscales (sleep problems, emotionally reactive, 
anxious/depressed, social withdrawal, somatic complaints, attention problems, and aggressive behavior). Seven items make up the "sleep problems" standardized subscale.

\section{Treatment evaluation questionnaires (TEQ)}

To evaluate the acceptance of all contents of the Mini-KiSS Online treatment, we constructed session-specific TEQ. These questionnaires were constructed with regard to three areas: first, to assess the acceptance of the specific contents of each treatment session; second, to provide an overall evaluation of the last session; finally, to evaluate the complete treatment. Parents rated on a five-point Likert scale ( 1 = was completely helpful for me; 2 = was rather helpful for me; 3 = I don't know; 4 = was rather not helpful for me; $5=$ was not at all helpful for me). The TEQs contained a free comment field at the end of the questionnaire. All questionnaires were collected after treatment.

\section{Procedure}

After the initial contact, families received a brief overview of the Mini-KiSS Online treatment as well as online questionnaires and materials. After signing an informed consent, families completed the CBCL 1.5-5, Mini-KiSS-Online Questionnaire, and sleep diaries over a 2 -week period (premeasurement) until the first session of the Mini-KiSS Online treatment. The treatment sessions consisted of written information, including instructions for duties and responsibilities, or further materials (as described below). All of the sessions were uploaded to a personal account on a weekly basis and were available for download during the entire treatment time. Families were given access to their online desk with a personalized username and password. Parents were autonomously responsible for downloading and working on the treatment sessions according to the written instructions. After the 6-week treatment, families were requested to proceed with the follow-up measurement with the same online questionnaires and sleep diaries. Standardization of the procedure was ensured by the use of standard emails for all contacts between the Mini-KiSS Online team and the participating families.

\section{Content of Mini-KiSS Online treatment}

Mini-KiSS Online was developed on the basis of the onsite treatment Mini-KiSS as a bibliographic intervention program with cognitive-behavioral and imaginative strategies. ${ }^{26}$ The audience is parents of children aged from 6 months to 4 years with behavioral sleep problems. The program contains six treatment sessions, so that parents are able to implement strategies in small steps over a period of 6 weeks. Each treatment session involves a sleep educational and parental behavioral part. A brief overview of the six treatment sessions is shown in Table 2. All contents are presented in a written format, conveniently designed as a workbook to record behavior plans and other exercise-related summaries. To implement sleep strategies, parents are provided with additional material: (1) a stuffed leopard is used to adopt hypnotherapeutic strategies such as imagination and breathing in an appropriate way for children; (2) short, calm bedtime stories are dispensed for daily use to allow observational learning for the children; (3) imaginative exercises are uploaded in audio format for the parents. Mini-KiSS Online treatment aims to inform parents about healthy and disrupted sleep behavior, to reduce negative cognition about children's sleep problems, to improve sleep hygiene and parental educational competence, to implement relaxation strategies for parents and children, and to adopt adequate problem-solving strategies for sleep-related problems.

\section{Statistical analysis and hypothesis}

All data analyses were performed with PASW (v 19.0; SPSS Inc, Chicago, IL). Gaussian distribution was tested via a Kolmogorov-Smirnov test. If Gaussian distribution was not given for metric mean values, a Wilcoxon test was used instead of a $t$-test, and a Friedman test instead of an analysis of variance. Nonmetric mean values were analyzed with a Chi-square test. The fixed significance level was $\alpha=5 \%$. In an efficacy subset analysis, patient data are often excluded from the analysis. Potential bias can be introduced by such exclusions and can increase the probability of type I errors. Therefore, we used the intent-to-treat method for all the pre- and post-calculations as a sufficient condition to obtain complete data on all subjects. ${ }^{55}$ In an intent-to-treat design, all patients are included, irrespective of whether the patient is still receiving or complying with the assigned treatment.

First, we expected that the TEQ would show high acceptance and compliance. Second, we hypothesized that sleep latency, night-time disruption, and night waking captured by the sleep diary and by the CBCL $1.5-5$ would be reduced. Third, it was assumed that the parental behavior evaluated by the Mini-KiSS Online Questionnaire would improve when comparing the pre- and postmeasurements.

\section{Results}

From the $\mathrm{N}=52$ parents with their 55 children starting the online treatment, $\mathrm{N}=28$ completed the postmeasurements. Follow-up data are not available yet. Analyses show that 
Table 2 Content of Mini-KiSS Online training

\begin{tabular}{|c|c|c|}
\hline Session & Contents & Methods \\
\hline I. Psychoeducation and first steps & $\begin{array}{l}\text { Information about day-night rhythm, sleep-cycle, sleep-duration, } \\
\text { functions of sleep, sleep disorders, influencing factors on sleep, } \\
\text { and daytime structure. Explanation about the use of bed-time-stories, } \\
\text { imagination CDs and homework (eg, planning a new bedtime-ritual) }\end{array}$ & $\begin{array}{l}\text { Psychoeducation I } \\
\text { Cognitive behavior therapy } \\
\text { Imaginations/imaginative } \\
\text { therapy }\end{array}$ \\
\hline $\begin{array}{l}\text { 2. Educational behavior and sleep } \\
\text { hygiene }\end{array}$ & $\begin{array}{l}\text { Information about sleep hygiene (part I), the relation of daytime } \\
\text { behavior and sleep, the importance of educational behavior, learning } \\
\text { behavior of children, token systems. How to use the stuffed leopard } \\
\text { in a proper way, implementing educational rules and instructions } \\
\text { of using the new imagination exercise and bedtime stories and how } \\
\text { to create a personalized token system are further contents } \\
\text { of this session }\end{array}$ & $\begin{array}{l}\text { Psychoeducation II } \\
\text { Behavior therapy } \\
\text { Reward systems } \\
\text { Using imaginations for children }\end{array}$ \\
\hline 3. Crying and defiantness & $\begin{array}{l}\text { Information about crying and appropriate tranquilization, reasons } \\
\text { for crying, defiantness, aggressive behavior, intervention strategies } \\
\text { for these topics, information about sleep environment (sleep hygiene } \\
\text { part 2), new imagination exercise and bedtime stories }\end{array}$ & $\begin{array}{l}\text { Psychoeducation III } \\
\text { Cognitive behavior therapy } \\
\text { Bedtime stories }\end{array}$ \\
\hline 4. Distress and relaxation & $\begin{array}{l}\text { Information about the influence of distress and relaxation for parents } \\
\text { on their educational behavior, how to use cognitive strategies, } \\
\text { instruction to adopt special play-times for the child and relaxation } \\
\text { times for the parents, new imagination exercise and bedtime stories }\end{array}$ & $\begin{array}{l}\text { Cognitive behavior therapy } \\
\text { Relaxation techniques } \\
\text { Imaginations }\end{array}$ \\
\hline 5. Anxieties and feeling of security & $\begin{array}{l}\text { Information about day and night anxieties of children, behavior } \\
\text { and intervention strategies, implementing a feeling of security, } \\
\text { information about the relation between sleep and feeding, relaxation } \\
\text { and massage for children, systematic integration of the knowledge } \\
\text { acquired from session one to five, new imagination exercise } \\
\text { and bedtime stories }\end{array}$ & $\begin{array}{l}\text { Cognitive behavior therapy } \\
\text { Relaxation techniques } \\
\text { Imaginations }\end{array}$ \\
\hline 6. Risk to comply and summarization & $\begin{array}{l}\text { Information about the risk to comply and intervention strategies, } \\
\text { typical pitfalls, calmness and attentiveness, summarization of useful } \\
\text { strategies for the family, repetition of sleep hygiene (part I) }\end{array}$ & Cognitive behavior therapy \\
\hline
\end{tabular}

families who completed the postmeasurements and families who dropped out did not differ in the following assessments: age and gender of the child, age and education of the parents, overall global rating of child's sleep, and various items about parental reaction to child sleep habits. However, families who completed all of the measurements were rated to be more negatively affected by the sleep problem of the child (22\%, $\mathrm{N}=5)$ than drop-outs $(\mathrm{N}=0 ; \mathrm{Z}=-2.462 ; P=0.014)$.

The key analysis was to evaluate the acceptance of MiniKiSS Online and the efficacy on the sleep habits of the child. In the following sections, we firstly describe the results of the TEQ as regards the acceptance of Mini-KiSS Online. For the subsequent efficacy analysis, we used the intentto-treat method to replace missing postmeasurements with premeasurements, so that all $\mathrm{N}=52$ starters were included. Therefore, we analyzed data from the sleep diary, the sleeprelated items of the CBCL 1.5-5, and the parental behavior aspects from the Mini-KiSS Online Questionnaire.

\section{Acceptance}

To measure the acceptance, parents rated all topics of MiniKiSS Online with the TEQ on a five-point Likert scale.
All six sessions were evaluated with a different number of questions (sessions one to six: 6 - 16 - 11 - 12 - 13 - 8 questions). Table 3 shows the preferred contents, rated with a mean value of two or less. All other contents are rated with a mean of $\mathrm{M}=2.1$ to $\mathrm{M}=3.88$, whereas the lowest evaluation, according to hypnotherapeutic strategies, was given to the stuffed leopard. Parents often noted that their children were too young to understand the imaginative strategies, whereas parents of older children ( $>2$ years of age) reported considerable success with these strategies. However, none of the items were rated with a mean of four or worse.

In addition to the content-specific evaluation, parents were asked to rate the entire previous treatment session on a weekly basis by providing an assessment for the same four positively phrased statements: (1) "The topics of the last treatment session appealed to me," (2) "I was able to transfer the general information to my personal situation," (3) "The last online session motivated me to continue working on the sleep problem of my child," (4) "I have the feeling that the sleep situation of my child has improved." The answer options were: $1=$ completely applies to me, 2 = rather applies to me, $3=$ I don't know, 
Table 3 Most preferred contents (mean $\leq 2)$

\begin{tabular}{|c|c|c|}
\hline Session & Topic/information about & Mean (SD) \\
\hline $\mathrm{I}$ & Human sleep & $1.85(0.92)$ \\
\hline I & $\begin{array}{l}\text { Sleep disorders and influencing } \\
\text { factors }\end{array}$ & $1.96(0.82)$ \\
\hline 2 & $\begin{array}{l}\text { Relationship between daytime } \\
\text { behavior and sleep at evening }\end{array}$ & $\mathrm{I} .54(0.7 \mathrm{I})$ \\
\hline 2 & Learning through consequences & $1.85(0.97)$ \\
\hline 2 & $\begin{array}{l}\text { Educational strategies } \\
\text { for consequent behavior }\end{array}$ & $1.76(0.78)$ \\
\hline 2 & $\begin{array}{l}\text { Educating strategies for } \\
\text { healthy sleep }\end{array}$ & $1.96(1.18)$ \\
\hline 2 & Creative problem solving & $1.96(0.89)$ \\
\hline 3 & $\begin{array}{l}\text { Behavior strategies for handling } \\
\text { crying and screaming situations }\end{array}$ & $2.00(1.10)$ \\
\hline 3 & Defiance behavior & $1.92(1.20)$ \\
\hline 4 & $\begin{array}{l}\text { Parental distress/stress-worsening } \\
\text { cognitions }\end{array}$ & $\begin{array}{l}1.96(0.87) / \\
1.73(0.72)\end{array}$ \\
\hline 4 & $\begin{array}{l}\text { Cognitive coping strategies against } \\
\text { distress }\end{array}$ & $1.73(0.92)$ \\
\hline 4 & $\begin{array}{l}\text { Time and attention for and with } \\
\text { the child }\end{array}$ & $\mathrm{I} .75(0.74)$ \\
\hline 5 & Feeling of security and anxiety & $1.73(0.87)$ \\
\hline 5 & Anxieties in childhood & $1.69(0.79)$ \\
\hline 5 & $\begin{array}{l}\text { Intervention strategies } \\
\text { for anxieties }\end{array}$ & $1.88(1.03)$ \\
\hline 5 & $\begin{array}{l}\text { Intervention strategies } \\
\text { for feeling of security }\end{array}$ & $1.85(1.05)$ \\
\hline 5 & $\begin{array}{l}\text { The importance of structuring } \\
\text { an intervention plan }\end{array}$ & $1.92(0.74)$ \\
\hline 6 & The risk to comply & $1.68(0.95)$ \\
\hline 6 & Calmness & $1.68(0.63)$ \\
\hline 6 & $\begin{array}{l}\text { Attentiveness/attention } \\
\text { for everyday occurrences }\end{array}$ & $\begin{array}{l}1.71(0.62) / \\
1.80(0.82)\end{array}$ \\
\hline
\end{tabular}

Notes: Item values: I = was completely helpful for me, 2 = was rather helpful for me, 3 = I don't know, 4 = was rather not helpful for me, 5 = was not at all helpful for me. Abbreviation: SD, standard deviation.

$4=$ rather doesn't apply to me, $5=$ doesn't apply to me at all. As indicated in Figure 1 for the first three statements, in mean, the treatment sessions rather appealed to the parents (statement 1), they were able to transfer general information to their personal situation (statement 2), and were motivated by all of the treatment sessions to continue working on the sleep problem of their child (statement 3 ). The findings seem to be stable over the 6 weeks of the Mini-KiSS Online.

Figure 2 shows the development of parental perception of their child's sleep improvement during treatment. In week 3, parents perceived a significant improvement compared to week $2(\mathrm{~T}=2.737 ; P=0.012)$ or week 1 ( $\mathrm{T}=2.824$; $P=0.010)$. This perceived improvement remained stable for the rest of the treatment.

At the end of the last practice week of session six, parents rated a few additional global statements with

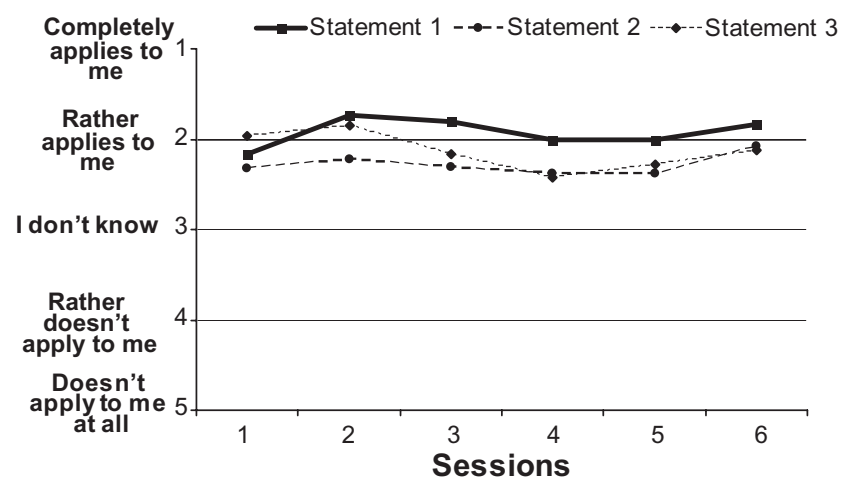

Figure I Results of the acceptance assessment of Mini-KiSS Online Questionnaire for statements I to 3 .*

Notes: *Statement I, "The topics of the last training session appealed to me"; statement 2, "I was able to transfer the general information to my personal situation"; statement 3, "The last online-session motivated me to continue working on the sleep problem of my child."

respect to the entire Mini-KiSS Online treatment. Answer categories were again: 1 = completely applies to me, $2=$ rather applies to me, $3=$ I don't know, 4 = rather doesn't apply to me, $5=$ doesn't apply to me at all. Table 4 indicates that all questions were rated quite positively. Above all, parents agreed that they would recommend the online treatment to other families with children suffering from sleep problems.

\section{Sleep behavior of the child: sleep diary}

Table 5 presents the significant improvements in nearly all parameters of the sleep diary after Mini-KiSS Online treatment. The frequency and duration of night waking of children decreased significantly as well as the need for external help to fall asleep (parental presence, feeding, co-sleeping, use of parental support). However, it should be noted that the premeasurement of average sleep onset latency was not above the clinical range of more than 30 minutes, according to Gaylor et al. ${ }^{52}$ Therefore, improvement in sleep onset latency could not be expected. Furthermore, problems with daytime sleep decreased significantly and overall sleep duration and sleep efficiency increased.

An intent-to-treat analysis showed significant interactions in the short-term efficacy assessment between treatment outcomes and the age of the children. A higher improvement in sleep efficiency was recorded in infants (pre: $84.76 \%$; post: $93.76 \%$ ) than in toddlers (pre: $90.07 \%$; post: $94.30 \%)(\mathrm{F}=3.168 ; P=0.052)$. Moreover, infants significantly reduced co-sleeping: three times more often (pre: 5.3 times/week; post: 1.6 times/week) than toddlers (pre: 4.5 times/week; post: 3.3 times/week) $(\mathrm{F}=4.132$; $P=0.023)$. 


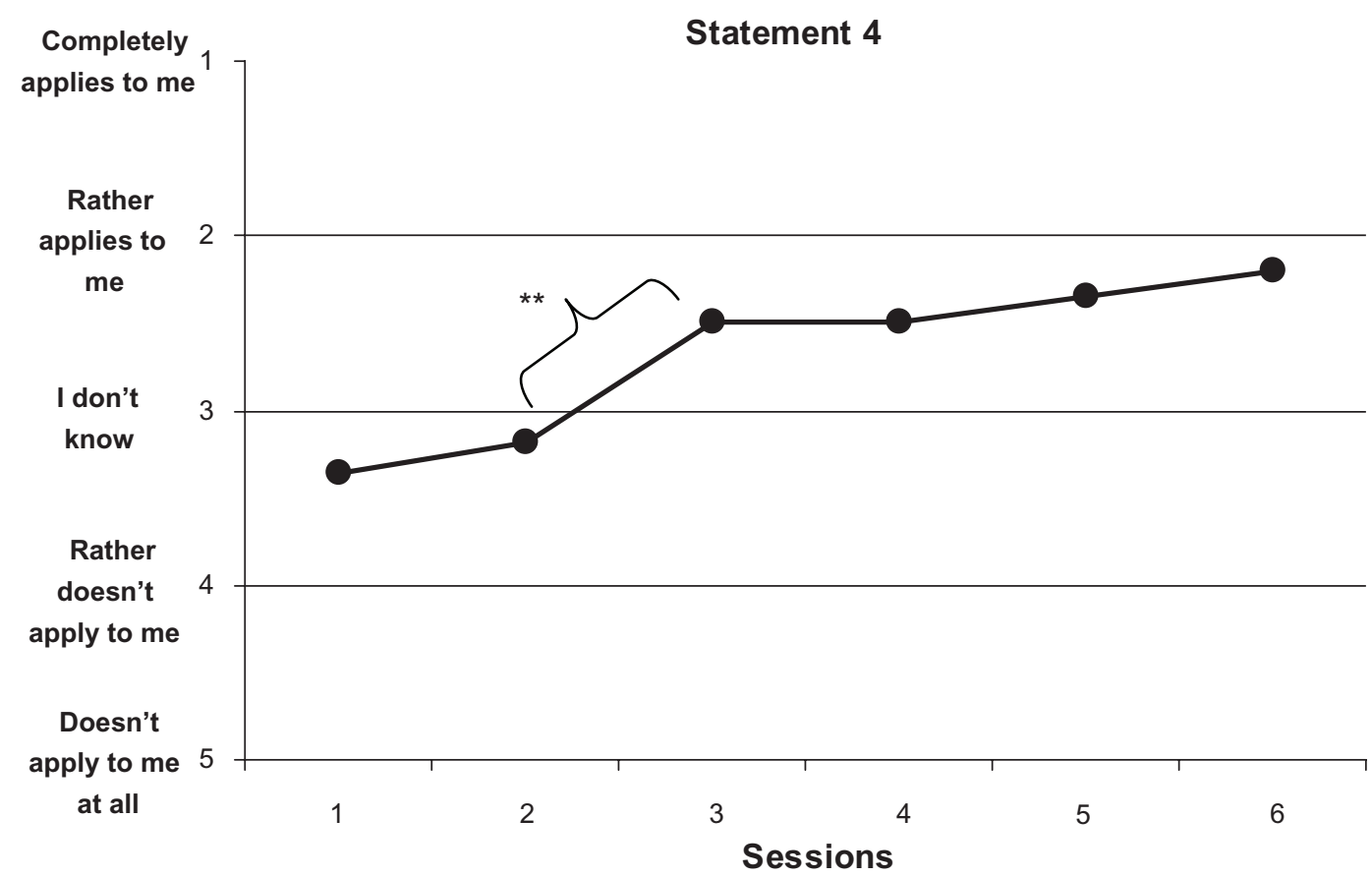

Figure 2 Results of the acceptance assessment of Mini-KiSS Online Questionnaire for statement 4.*

Notes: *Statement 4, "I have the feeling that the sleep situation of my child has improved." **Significant differences $(P=0.0 \mathrm{I})$.

\section{Sleep behavior of the child: CBCL I.5-5}

For detailed results about the distinctive sleep habits of the child, we calculated the standardized sleep subscale of the CBCL $1.5-5$ as well as all sleep-related items in particular. As shown in Table 6, parents rated all sleep-related items significantly less problematically after Mini-KiSS Online, with the exception of talking, crying, or sleeping at night ("Child talks, cries or screams while sleeping") $(0=$ not applicable, $1=$ somewhat or sometimes applicable, 2 = exactly or often applicable). Therefore, the T-transformed sleep subscale showed a significant

Table 4 Global statements about Mini-KiSS Online training

Statements

I. I believe that in the future I will be able to handle the sleep problem of my child

2. The Online training answered nearly all of my questions

3. The Online training helped me to better understand the sleep behavior of my child

4. I am glad that I participated in the Online training

5. I would recommend the Online training to other families with sleep problems

6. The questionnaires helped me to better understand the sleep problem

7. I was able to cope well with the organization of the Online training

Notes: Item values: I = completely applies to me, 2 = rather applies to me $3=1$ don't know, 4 = rather doesn't apply to me, $5=$ doesn't apply to me at all. Abbreviation: SD, standard deviation.

$2.52(1.26)$

$1.83(1.17)$

$1.64(0.99)$

$1.40(0.82)$

1.88 (1.20)

$1.80(0.87)$ reduction after treatment. CBCL results were in accordance with the sleep diary results represented above.

In order to prove age and time effects, we compared the global CBCL 1.5-5 sleep subscale for children aged 18 months or younger $(\mathrm{N}=31)$ to that of children aged 19 months or older $(\mathrm{N}=24)$. Younger children $(\mathrm{M}=65.23)$ did not differ significantly from older children $(\mathrm{M}=65.50$; $\mathrm{T}=-0.111 ; P=0.912)$ in premeasurement. This indicates that the reduction in the CBCL 1.5-5 sleep subscale between the pre- and postmeasurements may not be due to age or time effects. Otherwise a lower mean value for older children would have been expected.

\section{Sleep behavior of the child: Mini-KiSS Online Questionnaire}

At the beginning of the Mini-KiSS Online Questionnaire, we asked parents to rate the overall recent sleep habits of the child on a ten-point Likert scale from " 1 = completely normal to $10=$ very problematic." In general, this value decreased significantly from premeasurement $(\mathrm{M}=7.43$; $\mathrm{SD}=1.41)$ to postmeasurement $(\mathrm{M}=3.39 ; \mathrm{SD}=1.95)$ $(\mathrm{T}=9.661 ; P=0.000)$.

\section{Parental behavior}

A further aim of this study was to investigate parental behavior, which is assumed to lead to improvement of the 
Table 5 Results of the sleep behavior of the child: sleep diary

\begin{tabular}{|c|c|c|c|c|c|c|c|}
\hline & Sleep diary results, $N=55$ & $\begin{array}{l}\text { Premeasures, } \\
\text { mean (SD) }\end{array}$ & $\begin{array}{l}\text { Postmeasures, } \\
\text { mean (SD) }\end{array}$ & Statistic & $P$-value & Wilks-lambda & $\begin{array}{l}\text { Effect size } \\
\left(e^{2} a^{2}\right)\end{array}$ \\
\hline \multirow[t]{4}{*}{ Sleep onset } & $\begin{array}{l}\text { Duration of going-to-bed-ritual } \\
\text { Minutes per evening }\end{array}$ & $21.25(11.91)^{\mathrm{a}}$ & $19.89(12.33)^{\mathrm{a}}$ & $\mathrm{T}=1.249$ & 0.217 & 0.971 & 0.029 \\
\hline & $\begin{array}{l}\text { Time of going to bed } \\
\text { SD in minutes }\end{array}$ & $20: 31(47.67)^{a}$ & $20: 03(48.66)^{a}$ & $\mathrm{~T}=-2.673$ & 0.010 & $0.88 I$ & 0.119 \\
\hline & $\begin{array}{l}\text { Sleep onset latency } \\
\text { Minutes }\end{array}$ & $19.97(15.55)^{\mathrm{a}}$ & $18.26(14.10)^{a}$ & $\mathrm{~T}=1.022$ & 0.311 & 0.981 & 0.019 \\
\hline & $\begin{array}{l}\text { Use of external support } \\
\text { to fall alseep } \\
\text { Number of nights per week }\end{array}$ & $4.89(2.96)^{b}$ & $4.02(3.22)^{\mathrm{b}}$ & $Z=-2.375$ & 0.018 & 0.901 & 0.099 \\
\hline \multirow[t]{6}{*}{ Sleep maintenance } & $\begin{array}{l}\text { Frequency of night wakings } \\
\text { Number per night }\end{array}$ & $3.10(2.08)^{\mathrm{a}}$ & $2.27(1.63)^{\mathrm{a}}$ & $\mathrm{T}=3.418$ & 0.001 & 0.819 & 0.181 \\
\hline & $\begin{array}{l}\text { Duration of night wakings } \\
\text { Minutes per night }\end{array}$ & $47.86(34.94)^{\mathrm{a}}$ & $35.34(34.53)^{\mathrm{a}}$ & $\mathrm{T}=3.97 \mathrm{I}$ & 0.000 & 0.771 & 0.229 \\
\hline & $\begin{array}{l}\text { If parents had to get up at night } \\
\text { Number per night }\end{array}$ & $1.98(1.97)^{\mathrm{a}}$ & $1.31(1.22)^{\mathrm{a}}$ & $\mathrm{T}=3.054$ & 0.004 & 0.850 & 0.150 \\
\hline & $\begin{array}{l}\text { Use of external support } \\
\text { to maintain sleep } \\
\text { Number of nights per week }\end{array}$ & $6.04(1.98)^{b}$ & $5.04(2.96)^{b}$ & $Z=-2.824$ & 0.005 & 0.857 & 0.143 \\
\hline & $\begin{array}{l}\text { Co-sleeping } \\
\text { Number of nights per week }\end{array}$ & $4.87(2.67)^{\mathrm{b}}$ & $4.00(2.98)^{b}$ & $Z=-3.394$ & 0.001 & 0.798 & 0.202 \\
\hline & $\begin{array}{l}\text { Nocturnal feeding } \\
\text { Number of nights per week }\end{array}$ & $4.63(2.87)^{\mathrm{b}}$ & $3.93(3.09)^{\mathrm{b}}$ & $Z=-2.4 I I$ & 0.016 & 0.884 & 0.116 \\
\hline \multirow[t]{2}{*}{ General } & $\begin{array}{l}\text { Overall sleep duration } \\
\text { Minutes per night }\end{array}$ & $599.33(52.04)^{\mathrm{a}}$ & $616.37(54.88)^{\mathrm{a}}$ & $\mathrm{T}=-3.222$ & 0.002 & 0.836 & 0.164 \\
\hline & $\begin{array}{l}\text { Sleep efficacy } \\
\text { In percent }\end{array}$ & $87.6 \mathrm{I}(6.26)^{\mathrm{a}}$ & $90.42(5.70)^{\mathrm{a}}$ & $\mathrm{T}=-4.084$ & 0.000 & 0.761 & 0.239 \\
\hline
\end{tabular}

Notes: Results were calculated via $t$-test or Wilcoxon test. Gaussian distribution was tested via Kolmogorov-Smirnov (K-S) test $(\alpha=0.05)$; ${ }^{\mathrm{K}}$-S test not significant; ${ }^{\mathrm{b}} \mathrm{K}-\mathrm{S}$ test significant.

Abbreviation: SD, standard deviation.

child's sleep. To assess the development of specific parental behavior strategies in sleep onset situations, we asked about particular behavior habits when the child refused to sleep. Parents rated several behavior strategies on a four-point Likert scale: $1=$ usually/often applicable (5-7 times a week), $2=$ sometimes (2-4 times a week), $3=$ rarely (once a week), or $4=$ not $/$ never applicable. Several inappropriate parental behavior strategies improved significantly after the MiniKiSS Online treatment in difficult sleep onset situations (see Table 7): allowing the child to get up again, staying with the child until they fell asleep, allowing the child to play or watch TV, telling another bedtime story, or scolding the child in the sleep onset situation. Further inappropriate parental behavior, such as feeding the child to sleep, allowing the child to start

Table 6 Results of the sleep behavior of the child: Child Behavior Checklist I.5-5 (CBCL I.5-5)

\begin{tabular}{|c|c|c|c|c|c|c|}
\hline CBCL, $\mathbf{N}=55$ & $\begin{array}{l}\text { Premeasures, } \\
\text { mean (SD) }\end{array}$ & $\begin{array}{l}\text { Postmeasures, } \\
\text { mean (SD) }\end{array}$ & Statistic & $P$-value & Wilks-lambda & $\begin{array}{l}\text { Effect size } \\
\left(\text { eta }^{2}\right)\end{array}$ \\
\hline \multicolumn{7}{|l|}{ CBCL sleep-subscale } \\
\hline T-transformed value & $65.35(8.99)^{\mathrm{a}}$ & $58.71(11.67)^{\mathrm{a}}$ & $\mathrm{T}=4.303$ & 0.000 & 0.745 & 0.255 \\
\hline Sleeping alone & $1.53(0.69)^{\mathrm{b}}$ & $1.09(0.87)^{\mathrm{b}}$ & $Z=-3.592$ & 0.000 & 0.751 & 0.249 \\
\hline Difficulties falling asleep & $1.38(0.78)^{b}$ & $0.95(0.87)^{b}$ & $Z=-3.403$ & 0.001 & 0.791 & 0.209 \\
\hline Nightmares & $0.35(0.55)^{\mathrm{b}}$ & $0.18(0.43)^{\mathrm{b}}$ & $Z=-3.000$ & 0.003 & 0.836 & 0.164 \\
\hline Refusing to go to bed in the evening & $0.7 \mathrm{I}(0.79)^{\mathrm{b}}$ & $0.42(0.57)^{\mathrm{b}}$ & $Z=-2.696$ & 0.007 & 0.871 & 0.129 \\
\hline Sleeping less than most other children at night & $0.84(0.88)^{\mathrm{b}}$ & $0.55(0.84)^{b}$ & $Z=-2.893$ & 0.004 & 0.845 & 0.155 \\
\hline Talking, crying, screaming while sleeping & $0.49(0.74)^{\mathrm{b}}$ & $0.55(0.69)^{\mathrm{b}}$ & $Z=-0.728$ & 0.467 & 0.990 & 0.010 \\
\hline Night wakings & $1.69(0.66)^{\mathrm{b}}$ & $1.24(0.84)^{\mathrm{b}}$ & $Z=-3.041$ & 0.002 & 0.807 & 0.193 \\
\hline
\end{tabular}

Notes: Item values: $0=$ not applicable, I = a bit or sometimes applicable, 2 = exactly or often applicable. Results were calculated via $t$-test or Wilcoxon test. Gaussian distribution was tested via Kolmogorov-Smirnov (K-S) test $(\alpha=0.05)$; ${ }^{a}$ K-S test not significant; ${ }^{b} \mathrm{~K}-\mathrm{S}$ test significant.

Abbreviation: SD, standard deviation. 
Table 7 Results of parental behavior changes in the sleep onset situation

\begin{tabular}{|c|c|c|c|c|c|c|}
\hline Mini-KiSS Online Questionnaire $(\mathbf{N}=55)$ & $\begin{array}{l}\text { Premeasures } \\
\text { mean (SD) }\end{array}$ & $\begin{array}{l}\text { Postmeasures } \\
\text { mean (SD) }\end{array}$ & Statistic & $P$-value & Wilks-lambda & $\begin{array}{l}\text { Effect size } \\
\left(\text { eta }^{2}\right)\end{array}$ \\
\hline Child gets something to eat or to drink & $2.65(1.26)$ & $2.79(1.26)$ & $Z=-1.889$ & 0.059 & 0.934 & 0.066 \\
\hline Child is allowed to get up again & $3.47(0.79)$ & $3.65(0.62)$ & $Z=-2.456$ & 0.014 & 0.899 & 0.101 \\
\hline Somebody stays with the child until it fell asleep & $1.60(1.07)$ & $2.00(1.16)$ & $Z=-3.068$ & 0.002 & 0.831 & 0.169 \\
\hline Child is allowed to start sleeping in parents' bed & $2.69(1.24)$ & $2.95(1.24)$ & $Z=-1.772$ & 0.076 & 0.945 & 0.055 \\
\hline Child is allowed to start sleeping next to the parents & $2.87(1.25)$ & $3.05(1.21)$ & $Z=-1.73 \mid$ & 0.083 & 0.943 & 0.057 \\
\hline Child is allowed to play or to watch TV & $3.85(0.4 I)$ & $3.94(0.23)$ & $Z=-2.236$ & 0.025 & 0.907 & 0.093 \\
\hline Child gets another bedtime-story or song & $2.63(1.22)$ & $3.00(1.16)$ & $Z=-2.838$ & 0.005 & 0.866 & 0.134 \\
\hline Parents scold the child & $3.35(0.78)$ & 3.51 (0.79) & $Z=-2.065$ & 0.039 & 0.922 & 0.078 \\
\hline Child gets medicine & $3.79(0.66)$ & $3.92(0.43)$ & $Z=-1.382$ & 0.167 & 0.960 & 0.040 \\
\hline
\end{tabular}

Note: Item values: I = usually/often applicable (5-7 times a week), $2=$ sometimes ( $2-4$ times a week), $3=$ rarely (once a week), or $4=$ not/never applicable. Results were calculated via Wilcoxon test because all variables failed Gaussian distribution (calculated via Kolmogorov-Smirnov test; $\alpha=0.05$ ).

Abbreviation: SD, standard deviation.

sleeping in the parents' bed or next to the parents, was also reduced, but failed to achieve statistical significance. Parental strategies, such as giving the child medicine to sleep, remained stable with a low frequency for both measurements.

Furthermore, we also assessed parental behavior strategies concerning night waking situations. The same four-point Likert scale was implemented. The following inadequate parental behavior strategies were reduced significantly after online treatment (see Table 8): soothing the child with food or drink, staying with the child until they fell asleep again, allowing the child to stay the night in the parents' bed, telling another bedtime story, scolding the child and taking the child out of its bed, or soothing the child in bed. Further inappropriate strategies, such as lying down next to the child, remained stable before and after online treatment. Additionally, parents used appropriate strategies, such as leaving the child to cry for a while to see if they were able to self-soothe, more often.

\section{Discussion}

The main goal of this study was to develop an online treatment for parents of children aged 6 months to 4 years suffering from insomnia. First of all, we wanted to explore the acceptance and the feasibility of such a treatment. Next, we focused on sleep-related problems, such as sleep onset latency, night waking, duration of night waking, and further sleep parameters.

The results of this study indicate that the Internet-based intervention Mini-KiSS Online is highly accepted by parents. Parents who completed the treatment would recommend the treatment to other families, were glad to participate in the treatment, and reported being able to deal with their children's sleep-related problems. These results are in line with the Mini-KiSS onsite treatment. ${ }^{26}$ Furthermore, the results showed that the treatment succeeded in improving nearly all aspects of sleep problems in young children, resulting in less difficulties falling asleep, less night waking, a higher ability

Table 8 Results of parental behavior changes in a night waking situation

\begin{tabular}{|c|c|c|c|c|c|c|}
\hline Mini-KiSS Online Questionnaire $(\mathbf{N}=55)$ & $\begin{array}{l}\text { Premeasures } \\
\text { mean (SD) }\end{array}$ & $\begin{array}{l}\text { Postmeasures } \\
\text { mean (SD) }\end{array}$ & Statistic & $P$-value & Wilks-lambda & $\begin{array}{l}\text { Effect size } \\
\left(\text { eta }^{2}\right)\end{array}$ \\
\hline Child gets something to eat/drink & $2.00(1.26)^{b}$ & $2.35(1.36)^{b}$ & $Z=-2.918$ & 0.004 & 0.847 & 0.153 \\
\hline Somebody stays with the child until it fell asleep & $1.67(1.12)^{b}$ & $2.11(1.21)^{\mathrm{a}}$ & $\mathrm{T}=-3.605$ & 0.001 & 0.806 & 0.194 \\
\hline Child is allowed to stay the night in the parents' bed & $1.95(1.16)^{b}$ & $2.31(1.27)^{\mathrm{a}}$ & $\mathrm{T}=3.112$ & 0.003 & 0.845 & 0.155 \\
\hline Child gets bedtime-story or song & $3.58(0.90)^{\mathrm{b}}$ & $3.76(0.74)^{b}$ & $Z=-2.157$ & 0.031 & 0.917 & 0.083 \\
\hline Parents scold the child & $3.47(0.74)^{\mathrm{b}}$ & $3.65(0.67)^{\mathrm{b}}$ & $Z=-2.233$ & 0.026 & 0.909 & 0.091 \\
\hline Parents take the child out of its bed and soothe it & $2.28(1.11)^{\mathrm{a}}$ & $2.76(1.08)^{\mathrm{a}}$ & $\mathrm{T}=-3.999$ & 0.000 & 0.768 & 0.232 \\
\hline Parents soothe the child in its bed & $1.98(1.04)^{\mathrm{a}}$ & $1.59(0.92)^{\mathrm{b}}$ & $\mathrm{T}=3.428$ & 0.001 & 0.819 & 0.181 \\
\hline Parents lay down next to the child & $2.94(1.3 \mathrm{I})^{\mathrm{b}}$ & $2.92(1.28)^{b}$ & $Z=-0.183$ & 0.855 & 1.000 & 0.000 \\
\hline $\begin{array}{l}\text { Parents leave the child to cry for a while and see if } \\
\text { child is able to self-soothe }\end{array}$ & $2.84(1.32)^{\mathrm{b}}$ & $2.28(1.29)^{\mathrm{a}}$ & $\mathrm{T}=4.006$ & 0.000 & 0.764 & 0.236 \\
\hline
\end{tabular}

Notes: Item values: I = usually/often applicable (5-7 times a week), $2=$ sometimes (2-4 times a week), $3=$ rarely (once a week), or $4=$ not/never applicable. Results were calculated via Wilcoxon test because all variables failed Gaussian distribution (calculated via Kolmogorov-Smirnov (K-S) test; $\alpha=0.05$ ). ${ }^{2} \mathrm{~K}-\mathrm{S}$ test not significant; ${ }^{\mathrm{b}} \mathrm{K}-\mathrm{S}$ test significant.

Abbreviation: SD, standard deviation. 
to sleep alone, significantly less resistance to going to bed, and less nightmares. All parameters changed significantly, not only in the questionnaires but also in the sleep diary. However, it has to be taken into account that the effect sizes were small to medium, which might be due to the small number of participants and the statistical intent-to-treat method. It is a very conservative method, which assumed that non-completers did not make any improvements and, therefore, were not willing to fill in the postmeasurement questionnaires.

Results of the CBCL 1.5-5 sleep subscale and items also showed significant decreases of nearly all aspects, despite the intent-to-treat analysis. Besides the significant reduction of the sleep-subscale, parents reported that their child was significantly more able to sleep alone and had fewer difficulties falling asleep. One can assume that the newly learned parental strategies, such as helping the child to self-soothe, establishing rules and bedtime routines, were successful for both parents and children. These results are in line with the findings of Mindell and colleagues. ${ }^{45}$

The intervention Mini-KiSS Online included a wide variety of parental behavior strategies as well as information about children's sleep and recommendations. Parents were instructed to identify the situations and recommendations specifically helpful for their child's problem. In contrast to the study of Mindell and colleagues, all parents participated in the same structured intervention program; no additional or variations of treatment conditions were included. ${ }^{45}$

According to the parents, the child's sleep changed after the second session. It could be discussed whether more sessions would have achieved a more significant improvement. As Howard and colleagues demonstrated, the attitude in therapy research is quite common that more sessions or trials are necessary to produce significant or clinical changes. ${ }^{56}$ The results show that the effect was initiated after the second session, but no further information is available on whether the next four sessions were necessary to establish and stabilize the changes that parents had initiated. Future research should keep this result in mind.

This study also shows that parents use the Internet as a source for sleep-related information and specific help. Therefore, our results indicate that parents of young children are interested in an Internet-based intervention and are able to change behavior during the intervention; these results are in line with those of Thorndike and Mindell and colleagues. ${ }^{45,57}$ Our findings match those of studies of online treatment for adults suffering from sleep problems, demonstrating the efficacy of an Internet-based intervention. ${ }^{42-44,58}$
When discussing the results of an online treatment, one has to bear in mind that sleep problems, such as bedtime resistance, frequent night waking, and the absence of self-soothing competence of the child, as well as other sleep-related problems, are highly common at a young age with prevalence rates of $9 \%$ to $54.2 \%{ }^{1-6}$ and a tendency to persistence and chronicity. ${ }^{6,13-15}$ Therefore, prevention and accessible treatments are necessary. An Internet-based intervention, as described in this study, fulfills all these requirements. However, several differences to an onsite therapy also have to be named. Firstly, parents were not personally contacted or treated by a therapist; therefore, unspecific therapy effects, such as therapeutic alliance or other therapeutic process variables as recommended by Grawe, were not fully active. ${ }^{59}$ Furthermore, in contrast to the onsite program, which was developed and verified first, ${ }^{26}$ this study was not conducted within small parental groups, which would have activated unspecific therapeutic group effects. ${ }^{60}$ Additionally, as parents were not in group therapy, as is frequently the case for onsite treatments, it may be hypothesized that the social desirability bias in the answers of the parents is lower, as they were not informed about the number of other parents participating in the project.

Several limitations have to be named. First, the high drop-out rate has to be mentioned. Although high dropout rates are more common in Internet-based studies, ranging from 2 to 98.97 percent, this should be critically discussed. ${ }^{61-64}$ Whereas drop-out rates seem to increase with free accessibility of treatment, ${ }^{63}$ they seem to decrease when online-treatment is supported by personal contacts. ${ }^{64,65}$ Our results showed that completer parents seemed to be more affected by the sleep problem of their child, which might be a motivational reason for not dropping out. Additionally, we were not able to determine at which stage in the treatment parents dropped out, as questionnaires were collected at the end. In order to produce results that are robust, we therefore replaced missing postmeasurements with premeasurements as an intent-to-treat method. ${ }^{55}$ Personal contact may also have reduced the drop-out rate of parents not completing the postmeasurement. ${ }^{66}$ Additionally, as mentioned previously, parents of older children ( $>2$ years of age) reported considerable success with imaginative strategies, whereas parents of younger children had problems with imaginative or hypnotherapeutic strategies. One may assume that problems with therapeutic strategies were responsible for drop-outs; however, drop-outs and completers showed no significant differences concerning age. 
Furthermore, this study did not include objective measurements, such as actigraphy, to evaluate the child's sleep. There were also no follow-up measurements, it is therefore not known whether the changes remained stable over the following months. Future studies of long-term outcomes are required. The focus of interest of this study was the acceptance and feasibility of the adapted version as an online treatment for parents with young children suffering from sleep problems.

Additionally, one may argue that the changes were due to time and not due to the treatment. Therefore, it cannot be assumed that all changes resulted from the intervention strategies. However, the treatment lasted only 6 weeks. Furthermore, younger children ( $\leq 18$ months) did not differ from older children ( $\geq 19$ months) in global sleep ratings of CBCL $1.5-5$ in premeasurement, which indicates that sleep problems do not decrease with age or time alone. Otherwise a lower mean value for older children would have been expected. Despite this argument, it would be helpful to establish a control group design in further studies. Finally, it is not clear which factors were helpful for the parents. Future studies are necessary to elucidate whether multi-component treatment is necessary, or whether there are certain basic intervention elements that might play a key role.

\section{Conclusion}

The intervention Mini-KiSS Online with its parental behavior strategies as well as information about children's sleep and recommendations is well accepted by parents and shows significant effects on children's sleep. The Internet-based intervention Mini-KiSS Online is beneficial in improving multiple aspects of infant and toddler sleep. The results show that the Internet can be effectively used for the treatment of insomnia at a young age.

\section{Disclosure}

The authors report no conflicts of interest in this work.

\section{References}

1. Bayer JK, Hiscock H, Hampton A, Wake M. Sleep problems in young infants and maternal mental physical health. J Paediatr Child H. 2007;43(1-2):66-73.

2. Burnham MM, Goodlin-Jones BL, Gaylor EE, Anders TF. Nighttime sleep-wake patterns and self-soothing from birth to one year of age: a longitudinal intervention study. J Child Psychol Psychiatry. 2002;43(6):713-725.

3. Hiscock H, Bayer J, Gold L, Hampton A, Ukoumunne OC, Wake M. Improving infant sleep and maternal mental health: a cluster randomised trial. Arch Dis Child. 2007;92(11):952-958.

4. Jenni OG, Fuhrer HZ, Iglowstein I, Molinari L, Largo RH. A longitudinal study of bed sharing and sleep problems among Swiss children in the first 10 years of life. Pediatrics. 2005;115(Suppl 1):233-240.
5. Matin J, Hiscock H, Hardy P, Davey B, Wake M. Adverse associations of infant and child sleep problems and parent health: an Australian population study. Pediatrics. 2007;119(5):947-955.

6. Wake M, Morton-Allen E, Poulakis Z, Hiscock H, Gallagher S, Oberklaid F. Prevalence, stability, and outcomes of cry-fuss and sleep problems in the first 2 years of life: prospective community-based study. Pediatrics. 2006;117(3):836-842.

7. Hiscock H, Wake M. Randomised controlled trial of behavioural infant sleep intervention to improve infant sleep and maternal mood. BMJ. 2002;324(7345):1062-1065.

8. Johnson CM. Infant and toddler sleep: a telephone survey of parents in one community. J Dev Behav Pediatr. 1991;12(2):108-114.

9. Lam P, Hiscock H, Wake M. Outcomes of infant sleep problems: a longitudinal study of sleep, behaviour and maternal well-being. Pediatrics. 2003;111(3):203-207.

10. Minde K, Popiel K, Leos N, Falkner S, Parker K, Handley-Derry M. The evaluation and treatment of sleep disturbances in young children. J Child Psychol Psychiatry. 1993;34(4):521-533.

11. Sadeh A, Flint-Ofir E, Tirosh T, Tikotzky L. Infant sleep and parental sleep-related cognitions. J Fam Psychol. 2007;21(1):74-87.

12. Tikotzky L, Sadeh A. Maternal sleep-related cognitions and infant sleep: a longitudinal study from pregnancy through the 1st year. Child Dev. 2009;80(3):860-874.

13. Petit D, Touchette E, Tremblay R, Boivin M, Montplaisir J. Dyssomnias and parasomnias in early childhood. Pediatrics. 2007;119(5): 1016-1025.

14. Pollock JI. Night waking at five years of age: predictors and prognosis. J Child Psychol Psychiatry. 1994;35(4):699-708.

15. Zuckermann B, Stevenson J, Bailey V. Sleep problems in early childhood: continuities, predictive factors, and behavioural correlates. Pediatrics. 1987;80(5):664-671.

16. Gais S, Plihal W, Wagner U, Born J. Early sleep triggers memory for early visual discrimination skills. Nat Neurosci. 2000;3(12):1335-1339.

17. Siegel J. The REM sleep-memory consolidation hypothesis. Science. 2001;294(5544):1058-1063.

18. Stickgold R. Sleep-dependent memory consolidation. Nature. 2005;437(7063):1272-1278.

19. Gregory AM, Eley TC, O’Connor TG, Plomin R. Etiologies of associations between childhood sleep and behavioural problems in a large twin sample. J Am Acad Child Psy. 2004;43(6):744-751.

20. Lavigne JV, Arend R, Rosenbaum D, et al. Sleep and behaviour problems among preschoolers. J Dev Behav Pediatr. 1999;20(3): $164-169$.

21. Wong MM, Brower KJ, Fitzgerald HE, Zucker RA. Sleep problems in early childhood and early onset of alcohol and other drug use in adolescence. Alcohol Clin Exp Res. 2004;28(4):578-587.

22. Dennis CL, Ross L. Relationships among infant sleep patterns, maternal fatigue, and development of depressive symptomatology. Birth. 2005;32(3):187-193.

23. Gelman VS, King NJ. Wellbeing of mothers with children exhibiting sleep disturbance. Aust J Psychol. 2001;53(1):18-22.

24. Hiscock H, Bayer JK, Hampton A, Ukoumunne OC, Wake M. Long-term mother and child mental health effects of a populationbased infant sleep intervention: cluster-randomized, controlled trial. Pediatrics. 2008;122(3):621-627.

25. Hiscock H, Wake M. Infant sleep problems and postnatal depression: a community-based study. Pediatrics. 2001;107(6):1317-1322.

26. Schlarb AA, Brandhorst I, Hautzinger M. Mini-KiSS-a multimodal group therapy intervention for parents of young children with sleep disorders: a pilot study. Z Kinder Jugendpsychiatr Psychother. 2011;39(3):197-206.

27. Mindell JA, Kuhn B, Lewin DS, Meltzer LJ, Sadeh A. Behavioural treatment of bedtime problems and night wakings in infants and young children. Sleep. 2006;29(10):1263-1276.

28. Schlarb AA, Velten-Schurian K, Poets CR, Hautzinger M. First effects of a multicomponent treatment for sleep disorders in children. Nat Sci Sleep. 2011;3:1-11. 
29. Moore M, Allison D, Rosen CL. A review of pediatric nonrespiratory sleep disorders. Chest. 2006;130(4):1252-1262.

30. Schlarb AA, Gulewitsch MD, Hautzinger M. Insomnien in der pädiatrischen Praxis: Häufigkeit, familiäre Belastung und Behandlungsempfehlungen. [Insomnia in pediatric care: Frequency, parents' burden, and treatment recommendations.] Somnologie. 2010;14(2):129-134. (German).

31. Mindell JA, Moline ML, Zendell SM, Brown LW, Fry JM. Pediatricians and sleep disorders: training and practice. Pediatrics. 1994;94(2): 194-200.

32. Owens JA. The practice of pediatric sleep medicine: results of a community survey. Pediatrics. 2001;108(3):e51.

33. Owens JA, Rosen CL, Mindell JA. Medication use in treatment of pediatric insomnia: results of a survey of community-based pediatricians. Pediatrics. 2003;111(5):628-635.

34. Owens JL, France KG, Wiggs L. Behavioural and cognitive-behavioural interventions for sleep disorders in infants and children: a review. Sleep Med Rev. 1999;3(4):281-302.

35. Sadeh A. Cognitive-behavioural treatment for childhood sleep disorders. Clin Psychol Rev. 2005;25(5):612-628.

36. Smere W, Karamanoukian HL, Levitt M, et al. A pediatric surgery study: parent usage of the Internet for medical information. J Pediatr Surg. 2003;38(4):560-564.

37. Andersson G, Bergström J, Carlbring P, Lindefors N. The use of the Internet in the treatment of anxiety disorders. Curr Opin Psychiatr. 2005;18(1):73-77.

38. Barak A, Hen L, Boniel-Nissim M, Shapira N. A comprehensive review and a meta-analysis of the effectiveness of Internet-based psychotherapeutic interventions. J Tech Hum Serv. 2008;26(2-4):109-160.

39. Christensen H, Griffiths KM, Jorm AF. Delivering interventions for depression by using the Internet: randomised controlled trial. BMJ. 2004;328(7434):265.

40. Saperstein SL, Atkinson NL, Gold RS. The impact of Internet use for weight loss. Obes Rev. 2007;8(5):459-465.

41. Wantland DJ, Portillo CJ, Holzemer WL, Slaughter R, McGhee EM. The effectiveness of web-based vs non-web-based interventions: a meta-analysis of behavioural change outcomes. $J$ Med Internet Res. 2004;6(4):e40.

42. Ström L, Pettersson R, Andersson G. Internet-based treatment for insomnia: a controlled evaluation. J Consult Clin Psych. 2004;72(1): $113-120$.

43. Vincent N, Lewycky S. Logging on for better sleep: RCT of the effectiveness of online-treatment for insomnia. Sleep. 2009;32(6):807-815.

44. Ritterband LM, Thorndike FP, Gonder-Frederick LA, et al. Efficacy of an Internet-based behavioural intervention for adults with insomnia. Arch Gen Psychiatry. 2009;66(7):692-698.

45. Mindell JA, Du Mond CE, Sadeh A, Telofski LS, Kulkarni N, Gunn E. Efficacy of an Internet-based intervention for infant and toddler sleep disturbances. Sleep. 2011;34(4):451-458.

46. Lambert MJ, Hansen NB, Finch AE. Patient-focused research: using patient outcome data to enhance treatment effects. J Consult Clin Psych. 2001;69(2):159-172.

47. Lutz W. Efficacy, effectiveness, and expected treatment progress in psychotherapy. J Clin Psychol. 2003;59(7):1-6.
48. Norcross JC, Lambert MJ. Psychotherapy relationships that work II. Psychotherapy. 2011;48(1):4-8.

49. Orlinsky DE, Ronnestad MH, Willutzki U. Fifty years of psychotherapy process-outcome research: continuity and change. In: Lambert MJ, editor. Bergin and Garfield's Handbook of Psychotherapy and Behaviour Change. 5th ed. New York, NY: Wiley; 2004:307-389.

50. Prochaska JO, Norcross JC. Systems of Psychotherapy: A Transtheoretical Analysis. 7th ed. Belmont, CA: Thomson Brooks/Cole Publishing Co; 2010 .

51. American Academy of Sleep Medicine. The International Classification of Sleep Disorders, (ICSD-2): Diagnostic and Coding Manual. 2nd ed. Westchester, IL: American Academy of Sleep Medicine; 2005.

52. Gaylor EE, Burnham MM, Goodlin-Jones BL, Anders TF. A longitudinal follow-up study of young children's sleep patterns using a developmental classification system. Behav Sleep Med. 2005;3(1):44-61.

53. Wiater A, Scheuermann P. Diagnostik von Schlafstörungen. [Diagnostics for sleep disorders.] Monatsschr Kinderh. 2007;155(7):600-607. (German).

54. Achenbach T, Rescorla L. Manual for the ASEBA Preschool Forms and Profiles. Burlington, VT: University of Vermont; 2000.

55. Mazumdar S, Liu KS, Houck PR, Reynolds CF. Intent-to-treat analysis for longitudinal clinical trials coping with the challenge of missing values. J Psychiatr Res. 1999;33(2):87-95.

56. Howard KI, Kopta SM, Krause MS, Orlinski DE. The dose-effect relationship in psychotherapy. Am Psychol. 1986;41(2):159-164.

57. Thorndike FP. Commentary: Interest in Internet interventions - an infant sleep program as illustration. J Pediatr Psychol. 2009;34(5): 470-473.

58. Ritterband LM, Gonder-Frederick L, Cox DJ, Clifton AD, West RW, Borowitz SM. Internet interventions: in review, in use, and into the future. Prof Psychol Res Pr. 2003;34(5):527-534.

59. Grawe K. Psychological Therapy. Cambridge: Hogrefe and Huber; 2004.

60. Yalom ID, Leszcz M. The Theory and Practice of Group Psychotherapy. 5th ed. New York, NY: Basic Books; 2005.

61. Kerlinger FN. Foundations of Behavioural Research. 3rd ed. New York, NY: Holt, Rinehart and Winston; 1986.

62. Cuijpers P, van Straten A, Andersson G. Internet-administered cognitive behaviour therapy for health problems: a systematic review. J Behav Med. 2008;31(2):169-177.

63. Farvolden P, Denisoff E, Selby P, Bagby RM, Rudy L. Usage and longitudinal effectiveness of a web-based self-help cognitive behavioural therapy program for panic disorder. $J$ Med Internet Res. 2005;7(1):e7.

64. Cuijpers P, Marks IM, van Straten A, Cavanagh K, Gega L, Andersson G. Computer-aided psychotherapy for anxiety disorders: a meta-analytic review. Cogn Behav Ther. 2009;38(2):66-82.

65. Spek V, Cuijpers P, Vyklicek I, Riper H, Keyzer J, Pop V. Internet-based cognitive behaviour therapy for symptoms of depression and anxiety: a meta-analysis. Psychol Med. 2007;37:319-328.

66. Cook C, Heath F, Thompson RL. A meta-analysis of response rates in web- or Internet-based surveys. Educ Psych Measurem. 2000;60(6):821-836.
Nature and Science of Sleep

\section{Publish your work in this journal}

Nature and Science of Sleep is an international, peer-reviewed, open access journal covering all aspects of sleep science and sleep medicine, including the neurophysiology and functions of sleep, the genetics of sleep, sleep and society, biological rhythms, dreaming, sleep disorders and therapy, and strategies to optimize healthy sleep. The journal welcomes

\section{Dovepress}

original research, clinical \& epidemiological studies, reviews \& evaluations, case reports and extended reports. The manuscript management system is completely online and includes a very quick and fair peerreview system, which is all easy to use. Visit http://www.dovepress.com/ testimonials.php to read real quotes from published authors. 